\title{
El aprendizaje de la entonación (des)cortés en español lengua extranjera (ELE)*
}

\author{
Empar Devís Herraiz \\ Marta Bartolí RigOL \\ Universidad de Barcelona
}

Recibido: 25 noviembre 2012 / Aceptado: 5 febrero 2013

ISSN: $1697-7467$

\begin{abstract}
The aim of this paper was to discover the features melodic politeness and impoliteness to use Spanish in their exchanges and thus to determine the improvements that are needed to improve the performance of Spanish as a teacher and try to avoid conflicts caused by misunderstandings of melodic type. The paper presents the results obtained from acoustic analysis of the data and its validation perceptive, and a series of didactic proposals that we considered very useful educational.
\end{abstract}

Keywords: Discourse analysis, politeness, didactic, Spanish foreign language.

\section{Learning Intonation (im)Politeness in Spanish Foreign Language}

RESUMEN: El objetivo del presente trabajo ha sido descubrir los rasgos melódicos corteses y descorteses que utilizan los españoles en sus intercambios y así poder determinar las mejoras que se precisan para perfeccionar la actuación docente de español como LE e intentar evitar los conflictos provocados por malentendidos de tipo melódico.

El trabajo presenta los resultados obtenidos, a partir del análisis acústico de los datos y su validación perceptiva, y una serie de propuestas didácticas que consideramos de gran utilidad docente.

Palabras clave: análisis del discurso, cortesía, didáctica, español LE.

\section{INTRODUCCIÓN}

La (des)cortesía en el diálogo cotidiano es un fenómeno expresado a través de recursos morfológicos, sintácticos, léxicos y semánticos, pero la participación del componente fónico también cumple un papel primordial a la hora de interpretar un enunciado como cortés o descortés. A nivel suprasegmental, la entonación de cortesía es de suma importancia por su marcado carácter cultural y porque ofrece formas que permiten evitar posibles conflictos y establecer una relación basada en la cordialidad y la cooperación entre los interlocutores, lo que, indudablemente, beneficia las relaciones sociales e interculturales. El desconocimiento

\footnotetext{
* La investigación está dentro del proyecto del MICINN (Ministerio de Ciencia e Innovación de España) «Fonocortesía: el componente fónico en la expresión de cortesía y descortesía verbales en español coloquial». Referencia: FFI2009-07034.
} 
de los usos más frecuentes en una LE puede provocar, en cambio, malentendidos que dificultan las relaciones sociales.

En ELE, por ejemplo, nos encontramos casos como el del español hablado por brasileños donde los malentendidos por transferencias melódicas de la L1 a la LE son frecuentes. En un estudio precedente (Devís, en prensa) hemos podido comprobar cómo los rasgos melódicos del español hablado por brasileños, por su semejanza con los identificados como rasgos corteses en español, provocan que un brasileño fácilmente sea interpretado como un hablante cortés, simpático y afable. En muchos casos el malentendido no se percibe como negativo pero pueden darse situaciones contextuales de mayor exigencia y formalidad, como en una reunión de negocios, donde sí que podría interpretarse como una entonación inadecuada.

El objetivo del presente trabajo ha sido, por tanto, mostrar los rasgos melódicos corteses y descorteses que utilizan los españoles en sus intercambios (Devís, 2011) y así poder determinar las mejoras que se precisan para perfeccionar la actuación docente de español como LE e intentar evitar los conflictos provocados por malentendidos de tipo melódico. El trabajo muestra los resultados obtenidos, a partir del análisis acústico de los datos y su validación perceptiva, y una serie de propuestas didácticas que consideramos de gran utilidad docente.

Las propuestas didácticas que ofrecemos están pensadas para alumnos extranjeros de español profesional, en concreto profesiones que exijan un trato directo con otras personas. Con estas características podemos distinguir profesiones como:

- la atención al cliente (asistencia, información, compraventa, etc.)

- ejecutivos, empresarios, directores etc. (profesiones donde haya una jerarquía establecida y el jefe tenga que ganarse la confianza de sus empleados)

- profesores

- locutores (políticos, periodistas)

- abogados, médicos, enfermeras, etc.

Controlar el funcionamiento de los rasgos melódicos (des)corteses aumentará en cualquiera de estos ámbitos la efectividad en la comunicación, la calidad del servicio y la satisfacción del interlocutor, conjuntamente con la formación cultural de dicho trabajador.

\section{Metodología}

Para el análisis de los datos se ha aplicado, en ambos estudios, el método de Análisis Melódico del Habla que presenta F. J. Cantero (2002) en su libro Teoría y Análisis de la entonación. El punto de partida es la definición de la entonación a partir de las variaciones de frecuencia fundamental (F0) que cumplen una función lingüística a lo largo de la emisión de voz (Cantero, 2002: 18). El autor considera que la entonación funciona en tres niveles:

Pre-lingüístico: Comprende los fenómenos del acento, el ritmo y la melodía, que funcionan solidariamente como elementos fónicos coestructuradores del discurso, al margen de cualquier otra dimensión significativa.

En este nivel, se considera la entonación como un "contenedor" lingüístico, integrando y delimitando las unidades del discurso. Es lo que Quilis (1993) llamaba "función delimi- 
tadora" y "función integradora" de la entonación. Los rasgos melódicos característicos de este nivel son rasgos fonéticos, bien concretos.

Lingüístico: Comprende las características melódicas cuyo rendimiento fonológico permite caracterizar y distinguir las unidades funcionales de la entonación, sus "signos lingüísticos".

En español fueron identificados ocho tonemas resultantes de la combinación de los rasgos fonológicos ${ }^{1}$ (/ \pm interrogativa, \pm suspendida, \pm enfática/) que conforman los cuatro tipos de entonación descritos por el autor (neutra, interrogativa, suspendida y enfática), cuyos patrones melódicos constituyen las melodías típicas del español (Cantero \& Font-Rotchés, 2007). Hasta el día de hoy se han encontrado doce patrones melódicos diferentes para el español, con sus variantes y márgenes de dispersión.

Paralingüístico: comprende las variantes melódicas de tales tonemas, dentro de los amplios márgenes de dispersión de cada uno de ellos.

Tales melodías permiten expresar emociones particulares, rasgos discursivos idiolectales o de la personalidad del hablante, e incluso pueden estar variablemente codificadas (como ocurre, por ejemplo, en la expresión de la "cortesía": Devís, 2011).

El método para el análisis de los tres niveles de entonación permite:

- segmentar la curva entonativa en segmentos tonales (normalmente, un segmento tonal por vocal, excepto en las inflexiones);

- analizar la entonación independiente de otros niveles de análisis lingüístico;

- analizar todos los fenómenos tonales del habla incluidos en la melodía (acento, ritmo y entonación).

Y comprende dos fases:

Fase acústica (descriptiva):

- extracción de la F0 del enunciado;

- determinación de los valores de F0 vocálicos; se identifican las vocales y se anota su valor medio;

- la sucesión de valores vocálicos genera una curva melódica esencial que elimina los valores irrelevantes;

- y, en último lugar, cada patrón melódico obtenido en $\mathrm{Hz}$ se estandariza en porcentajes para construir una melodía independiente de las características del hablante.

Fase perceptiva (experimental):

- se sintetiza la melodía resultante mediante el programa de análisis acústico PRAAT: doing phonetics by computer y se substituyen los valores tonales por los valores estandarizados;

- se modifican únicamente los valores, cuya relevancia queremos comprobar;

- se realiza un experimento perceptivo que permita validar la melodía sintetizada y/o falsar la hipótesis melódica.

\footnotetext{
${ }^{1}$ Los rasgos fonológicos descritos en este nivel son rasgos abstractos, meramente opositivos.
} 


\section{Corpus}

Los datos que nos han permitido identificar los rasgos melódicos de (des)cortesía en español los hemos extraído de enunciados de la conversación etiquetada VALESCO_084.A1.

Val.Es.Co. (Valencia, Español Coloquial) ${ }^{2}$ constituye un grupo de investigación surgido en el seno del Departamento de Filología Española de la Universidad de Valencia en 1990. Su principal objeto de estudio fue desde el principio el español coloquial. La hipótesis inicial era que el funcionamiento de la conversación coloquial podía explicarse, no como transgresión de la gramática oracional, sino como conjunto de estructuras y estrategias, de base pragmática, constituidas en el proceso de interacción. El corpus está digitalizado en su totalidad y transcrito merced al Proyecto "Transcripción y digitalización del corpus Val. Es.Co. (Valencia, Español Coloquial)", dirigido hasta diciembre de 2008 por S. Pons, y al proyecto Fonocortesía aprobado en el 2010.

En cambio, los corpora utilizados para validar los rasgos identificados en la fase acústica fueron creados ad hoc para asegurarnos de que los originales eran, claramente, enunciados descorteses (en el primer test de validación) y corteses (en segundo), desde el punto de vista léxico-gramatical, y que los rasgos, exclusivamente melódicos, introducidos en las manipulaciones eran los únicos responsables de aportar atenuación (en el primer caso) y descortesía (en el segundo).

\section{Descripición de LOS RASGos MELódicos (DES)CORTESES EN ESPAÑol}

\subsection{Código de cortesía ${ }^{3}$}

Los datos analizados en la fase acústica nos permitieron elaborar la siguiente hipótesis sobre los rasgos melódicos responsables de mitigar enunciados que podrían contener algún tipo de "agresividad" léxico-gramatical implícita.

1) Desde el punto de vista de la entonación lingüística ${ }^{4}$.

\begin{tabular}{|c|}
\hline Inflexiones finales \\
\hline + suspendida: \\
(con ascenso final entre el 15\% y el 70\%) \\
\hline + interrogativa \\
\hline + enfática circunfleja: ascendente-descendente; descendente-ascendente. \\
\hline
\end{tabular}

\footnotetext{
${ }^{2}$ Ver http://www.valesco.es/

${ }^{3}$ los rasgos melódicos de la (des)cortesía no forman parte del código lingüístico de la lengua (que en la entonación serían exclusivamente los rasgos fonológicos) compartido por todos los hablantes del idioma. Es decir, no todos los hablantes marcan la cortesía de la misma manera, ni obedeciendo al mismo código. Sin embargo, podemos considerar que la (des)cortesía se inscribe en un nivel de análisis de la entonación que está muy cerca de constituir un código estable o semiestable: socialmente compartido, muy cercano al código lingüístico (Cantero y Mateo, 2011).

${ }^{4}$ La entonación lingüística comprende las características melódicas cuyo rendimiento fonológico permite caracterizar y distinguir las unidades funcionales de la entonación, sus "signos lingüísticos" (Cantero, 2002).
} 
2) Desde el punto de vista de la entonación paralingüísticas.

\begin{tabular}{|c|}
\hline $\begin{array}{c}\text { Rasgos de énfasis } \\
\text { (foco ancho) }\end{array}$ \\
\hline Prominencia en átonas \\
\hline Inflexiones internas \\
\hline Registro tonal bajo \\
\hline Primer pico desplazado o ausente \\
\hline
\end{tabular}

\begin{tabular}{|c|}
\hline $\begin{array}{c}\text { Rasgos de énfasis de palabra } \\
\text { (foco estrecho) }\end{array}$ \\
\hline Énfasis de palabra con inflexión circunfleja \\
\hline Énfasis de palabra con inflexión \\
+ interrogativa \\
\hline
\end{tabular}

El código que pudimos elaborar a partir de la fase acústica y de su sucesiva validación en la fase perceptiva nos permitió definir los modelos melódicos más rentables capaces de convertir, por ejemplo, órdenes en ruegos y confrontaciones en cooperaciones. Mostramos los cinco más rentables por orden de eficacia, a partir de los porcentajes extraídos de las pruebas perceptivas:

- la combinación de inflexiones internas más una inflexión final suspensa

- la combinación de inflexiones internas más una inflexión final circunfleja ascendentedescendente.

- la combinación de prominencias en átonas más una inflexión final suspensa

- la combinación de inflexiones internas más una inflexión final interrogativa

- la combinación de prominencias en átonas más una inflexión final circunfleja ascendente-descendente.

\footnotetext{
${ }^{5}$ La entonación paralingüística permite expresar emociones particulares, rasgos discursivos idiolectales o de la personalidad del hablante, e incluso puede estar variablemente codificada, como en el caso de la (des)cortesía (Cantero, 2002).
} 


\subsubsection{Ejemplos}

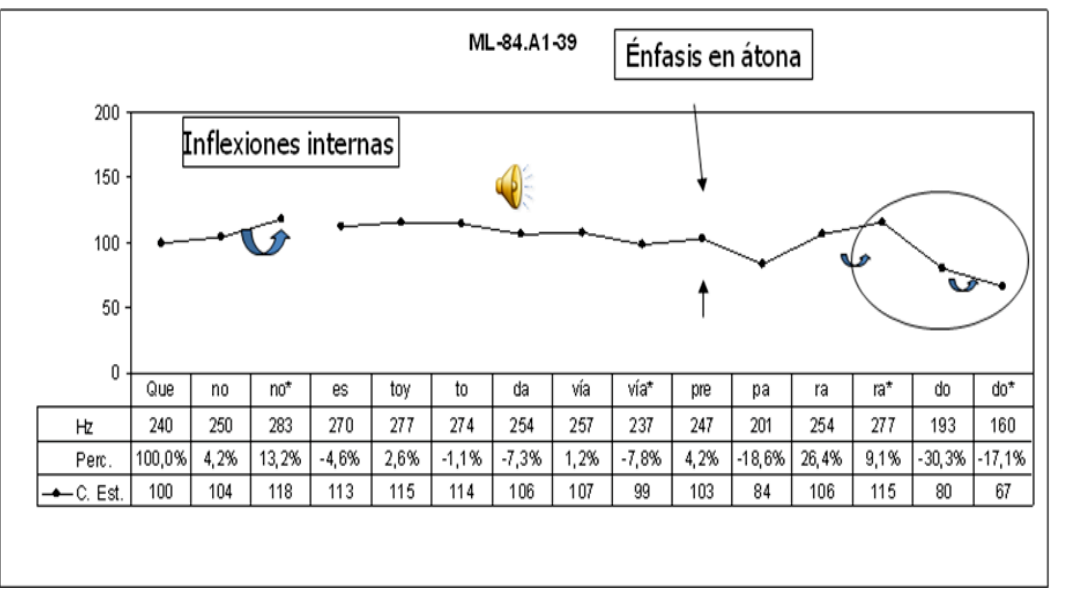

Figura 1. Melodía estandarizada del enunciado: "Que no estoy todavía preparado"

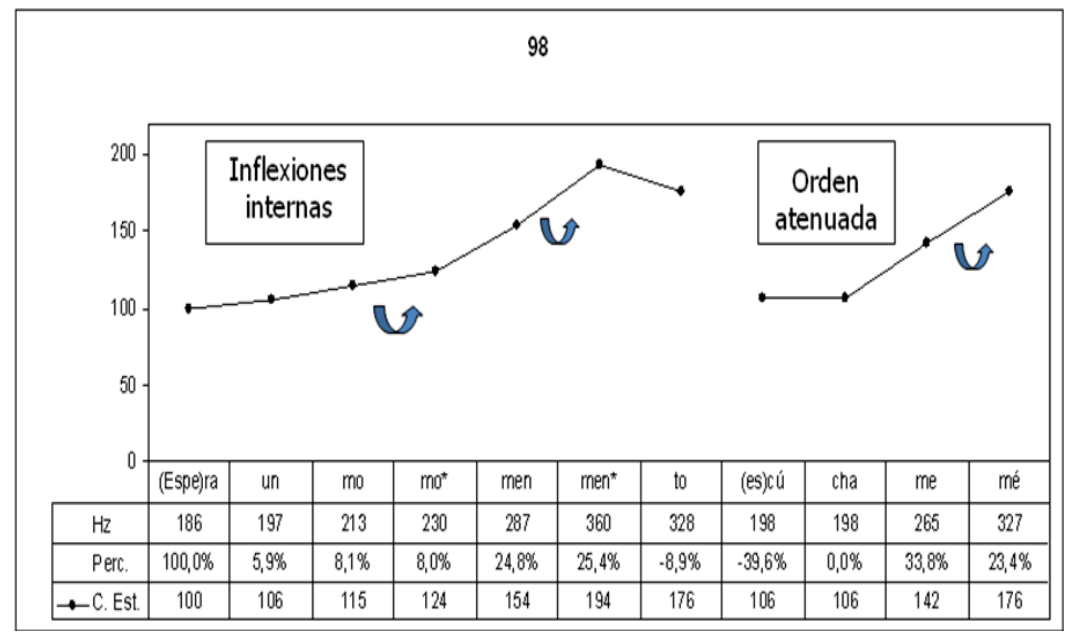

Figura 2. Melodia estandarizada del enunciado: "Espera un momento, escúchame"

La figura 2 presenta dos grupos fónicos: en el primero "espera un momento" observamos una declinación ascendente $(+50,2 \%)$ con final neutro (- 8,9\%), y en el segundo "escúchame" aparece una inflexión suspendida $(+57,2 \%)$, desde el punto de vista de la entonación 
lingüística ${ }^{6}$, que, en este contexto, a nivel pragmático funciona como rasgo atenuador para mitigar la agresividad implícita de la orden. Esta transposición funcional del contorno entonativo (+ suspendido) que a nivel pragmático actúa como mecanismo atenuador ya había sido identificado precedentemente por Hidalgo (2009). Las inflexiones internas, en cambio, desde el punto de vista de la entonación paralingüística ${ }^{7}$, se convierten en claves acústicas relevantes para distinguir un enunciado cortés de uno neutro, son énfasis de foco ancho muy recurrentes en todos los ejemplos analizados generando un ritmo melódico que distingue y caracteriza las emisiones corteses atenuadoras.

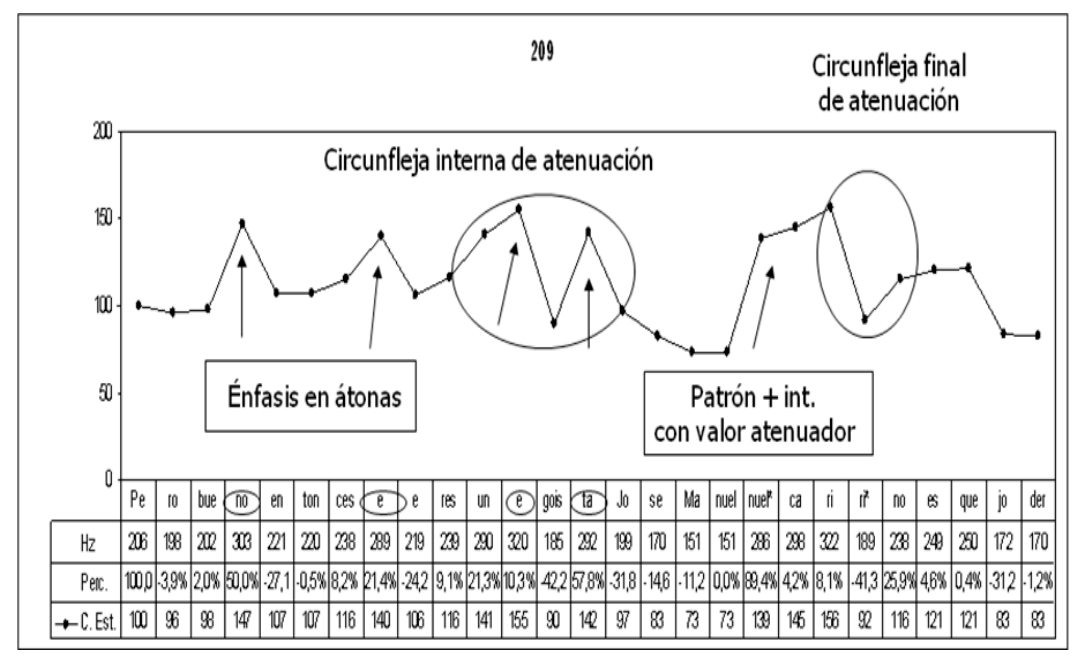

Figura 3. Melodía estandarizada del enunciado: "Pero bueno entonces eres un egoísta, José Manuel, cariño, es que joder"

La figura 3 muestra algunos de los rasgos identificados: los énfasis en átonas, la circunfleja interna de atenuación, la circunfleja final. Pero, además, observamos el patrón (+ interrogativo) con valor atenuador, como rasgo de énfasis en el vocativo "José Manuel", por lo tanto se trata de un énfasis de foco estrecho que se situaría en el nivel paralingüístico.

\subsection{Código de descortesía}

Los datos analizados en la fase acústica nos permitieron elaborar la siguiente hipótesis sobre los rasgos melódicos responsables de expresar descortesía usando la intensificación como estrategia discursiva:

\footnotetext{
${ }^{6}$ Por nivel lingüístico nos referimos al segundo nivel de entonación descrito por Cantero (2002).

${ }^{7}$ El nivel paralingüístico es el tercer nivel de entonación descrito por Cantero (2002).
} 
- inflexiones finales descendentes iguales o superiores al 30\% (en ocasiones con varios segmentos y a menudo con pico elevado);

- esquema con un único pico;

- prominencias en átonas muy marcadas (superiores al 50\%);

- esquema en zig-zag con contornos interiores muy ascendentes (normalmente entre el $20 \%$ y el $40 \%$, aunque hay casos de hasta el $60 \%$ y el $90 \%$ );

- énfasis de palabra con ascensos de hasta el $90 \%$.

El código que pudimos elaborar a partir de la fase acústica y de su sucesiva validación en la fase perceptiva nos permitió definir los modelos melódicos más rentables capaces de convertir, por ejemplo, halagos en ofensas, ruegos en órdenes y cooperaciones en confrontaciones. Mostramos los dos más rentables por orden de eficacia, a partir de los porcentajes extraídos de las pruebas perceptivas:

1. la introducción de más de un énfasis de palabra constituyendo un contorno en zig-zag (con ascensos sobre las vocales tónicas superior al 50\%);

2. la combinación de prominencias en átonas (con un ascenso superior al 50\%) más una inflexión final descendente (superior al 30\%).

\subsubsection{Ejemplos}

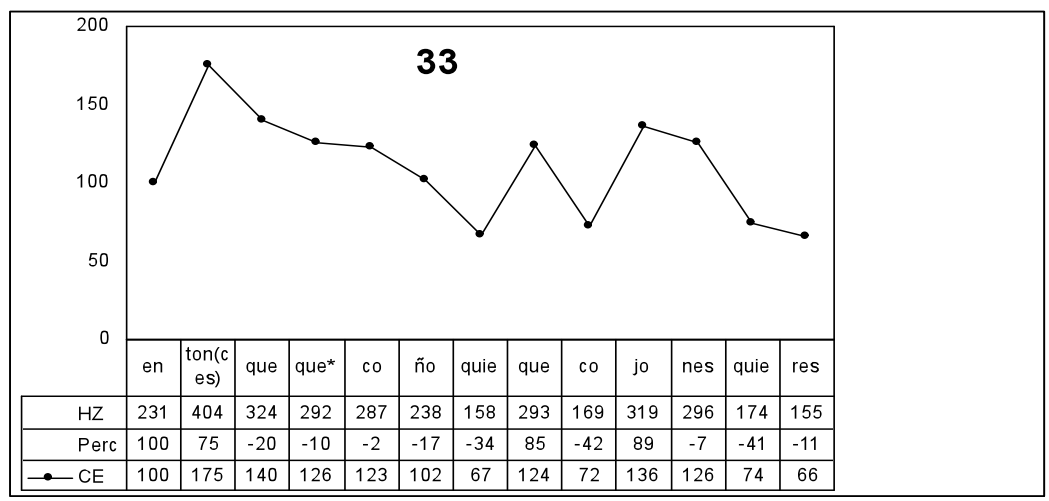

Figura 4. Melodía estandarizada del enunciado: "Entonces qué coño quieres, que cojones quieres"

La figura 4 presenta un esquema en zig-zag, ya descrito como rasgo de énfasis en Cantero et al (2005). Este es uno de los rasgos melódicos de énfasis más característicos del habla espontánea, y lo hemos hallado en numerosos enunciados. Lo más común es encontrar un zig-zag levemente descendente donde observamos la declinación en dientes de sierra que se resitúa ligeramente con el énfasis en la palabra "cojones", a partir del cual se establece la inflexión final descendente. El efecto conseguido a nivel pragmático por este tipo de esquema es el de provocación e incitación a la confrontación. 
Es un ejemplo de descortesía directa donde el acto amenazante se realiza de forma clara, con la intención de atacar la imagen positiva del interlocutor.

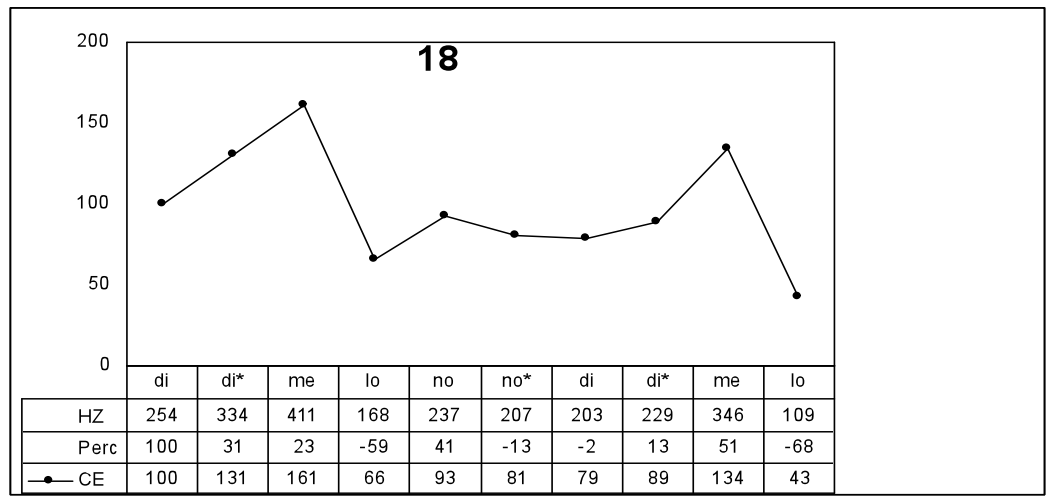

Figura 5. Melodía estandarizada del enunciado: "dímelo, no, dímelo"

La fig. 5 muestra un rasgo ya descrito en Devís (2011) como rasgo atenuador, se trata de la prominencia en vocales átonas. La diferencia es que cuando el énfasis tiene efecto atenuador la prominencia no supera nunca el $50 \%$ de ascenso (siendo lo más habitual un ascenso del 15\% al 30\%), mientras que en los casos donde el énfasis o intensificación actúa a nivel pragmático para ofrecer un efecto descortés, las prominencias en átonas superan en todos los casos el 50\% de ascenso. La inflexión final del enunciado, en cambio, vuelve a ser descendente. Es un ejemplo de descortesía encubierta donde el acto amenazante se realiza de forma sarcástica.

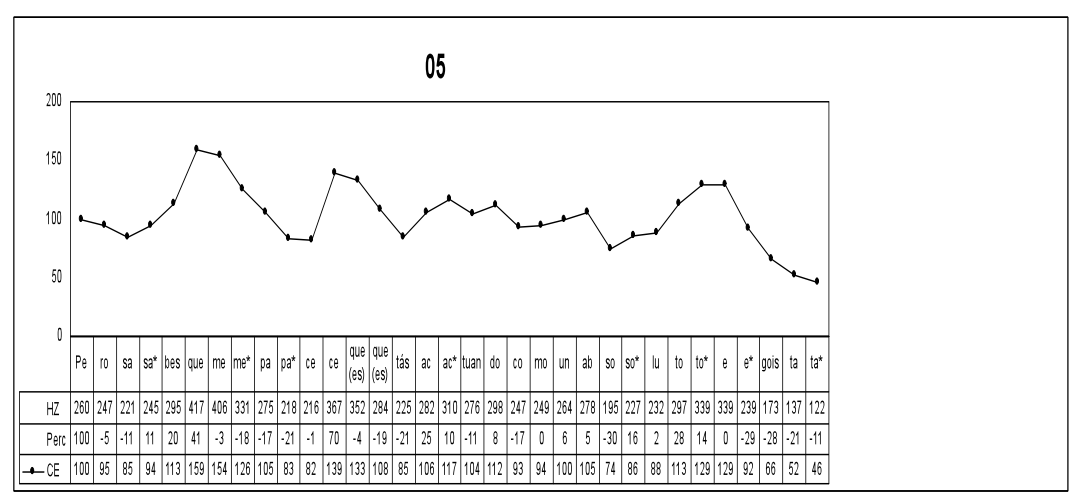

Figura 6. Melodía estandarizada del enunciado: "Pero sabes qué me parece que estás actuando como un absoluto egoísta" 
La figura 6 presenta el mismo esquema en zig-zag levemente descendente que se resitúa ligeramente con el énfasis en la palabra "absoluto", a partir del cual se establece la inflexión final descendente.

Es un ejemplo de descortesía negativa que apunta a dañar la imagen del destinatario ofreciéndole una imagen negativa.

\section{Propuestas didácticas}

Hemos desarrollado un total de cinco actividades destinadas a un nivel avanzado con el objetivo de poner en práctica la entonación de (des)cortesía. Nuestra propuesta se orienta a un nivel avanzado, porque queremos centrarnos exclusivamente en la entonación y por tanto, damos por conocidos los recursos morfológicos, sintácticos y léxicos para producir un discurso (des)cortés. Por este motivo, sugeriremos sólo las funciones lingüísticas con las que podría trabajarse, pero no nos centraremos en su estudio. Para estas tres actividades, hemos decidido partir de una actividad común y una breve práctica derivada de esta. Se trata de realizar una primera actividad destinada a la percepción y a la producción de la entonación de (des)cortesía, tras la cual habría la opción de realizar cualquiera de las tres actividades propuestas.

\subsection{Primera actividad introductoria común}

Esta primera actividad consiste en la audición de un fragmento de una riña entre una pareja de novios, en la que pueden apreciarse claramente intervenciones con entonación cortés y descortés.

La actividad se divide en dos partes. En la primera se realiza una audición como práctica de la percepción de la entonación de (des)cortesía y, en la segunda, se pone en práctica en la producción.

\section{Primera parte:}

Objetivo: identificar la (des)cortesía.

Nivel: $\mathrm{C} 1$

Tiempo: (7 min. 29 s.)

Destrezas: comprensión auditiva

Tipo de agrupamiento en clase: gran grupo y parejas

Material: VALESCO_084.A1

\section{Descripción}

Primero, pediremos a los alumnos que escriban en parejas una lista de temas de discusión entre novios. Pasados unos cinco minutos, se comentan entre todos y se elabora una 
lista conjunta. A continuación, les informamos de que escucharemos un fragmento de una discusión de pareja y que tienen que identificar el motivo y las frases que les resulten más (des)corteses. Pasamos el audio dos veces y les dejamos unos minutos para que comenten sus resultados. Transcurrido este tiempo, se comentan los datos entre todos. A continuación, les mostramos y examinamos varias frases obtenidas del corpus de investigación en las que pueden observarse los rasgos de cortesía atenuadora y descortesía.

\section{Segunda parte:}

Objetivo: producir enunciados corteses y descorteses e identificarlos

Nivel: $\mathrm{C} 1$

Tiempo: 10 minutos

Destrezas: comprensión y expresión orales

Tipo de agrupamiento en clase: en parejas

Material: tarjetas

Los estudiantes trabajarán en parejas la producción y la percepción de la entonación (des)cortés. Para ello, habrá un alumno A y un alumno B. El profesor proporcionará oralmente dos frases cortas a los alumnos A y dos más a los alumnos B. También dará un par de tarjetas a cada alumno con la palabra cortés o descortés. Los alumnos pueden recibir tarjetas iguales o diferentes. La actividad consiste en dar a la frase una entonación cortés o descortés según la tarjeta que hayan recibido e identificar la entonación. La actividad puede realizarse de forma alternativa. Primero interviene por ejemplo el alumno A y el B identifica la entonación; después, le corresponde el turno a $\mathrm{A}$ en la producción y a $\mathrm{B}$, en la percepción e identificación.

Si se considera necesario, puede realizarse una práctica adicional. Se proporcionan entonces más frases, pero por escrito para que la actividad se desarrolle con más agilidad. Los alumnos deciden entonces qué entonación quieren dar a cada frase y los compañeros la identifican.

\subsection{Propuesta de actividades}

\subsubsection{Primera actividad: El conflicto}

Objetivo: producir enunciados corteses y descorteses

Nivel: $\mathrm{C} 1$

Tiempo: $10-15$ minutos

Destrezas: interacción

Tipo de agrupamiento en clase: en parejas

Material: tarjetas 
Esta actividad tiene como objetivo poner en práctica la entonación de (des)cortesía $\mathrm{y}$, al mismo tiempo, repasar algunas funciones lingüísticas correspondientes al nivel $\mathrm{C}^{8}$ tales como "expresar enfado e indignación", "expresar sorpresa y extrañeza" y "reprochar." Como introducción a la actividad, podemos hablar sobre pequeños conflictos entre familiares, amigos, novios, vecinos, compañeros de trabajo, etc. y las soluciones a las que se ha llegado, si las ha habido, y qué consecuencias han tenido esos problemas en la relación a partir de ese momento. Tras la introducción al tema, explicamos a los estudiantes que se han producido varios conflictos entre uno de ellos y el resto. Se trata de un alumno que se ha comportado mal con casi toda la clase y algunos de ellos están enfadados con él. Otros, en cambio, se muestran menos disgustados y más dispuestos a perdonarlo y a olvidar la trastada que les ha hecho.

Una vez hemos situado a los estudiantes en el contexto, ya podemos iniciar la actividad. Se trata de un juego que consiste en adivinar el suceso o la mala pasada. Para ello, un estudiante tiene que salir del aula unos minutos. El resto de la clase decide el motivo o los motivos (no deberían ser más de tres) por el que están molestos con él y reflexionan sobre todo lo que le dirán para mostrarle su irritación y enfado. Los estudiantes tienen que decidir qué le dirán y cómo, es decir, qué entonación van a utilizar. El profesor deberá comentar al alumno "conflictivo" que su actitud tiene que ser conciliadora e intentar convencer a los compañeros que su comportamiento forma parte de su personalidad y que, en ningún caso, actúa de mala fe, simplemente es espontáneo y no piensa en las consecuencias que sus actos puedan tener. Trascurridos unos cinco minutos aproximadamente, el alumno puede entrar y volver a su sitio. Es importante que el resto de la clase pueda verlo y viceversa. Si desde el sitio habitual no fuera posible, es recomendable que se sitúe en otro lugar o en el centro del aula.

En este momento, ya pueden iniciarse las primeras intervenciones de los alumnos dirigidas al autor de las jugarretas. Es importante que le informemos del número de trastadas. Como el autor no sabe de qué se trata tiene que, por un lado, adivinar qué ha hecho exactamente $\mathrm{y}$, por otro, mostrarse conciliador (atenuación).

\subsubsection{Segunda actividad: La pareja}

Objetivo: producir la entonación de (des)cortesía

Nivel: $\mathrm{C} 1$

Tiempo: 10 minutos

Destrezas: interacción

Tipo de agrupamiento en clase: en parejas

Material: tarjetas

\footnotetext{
${ }^{8}$ Inventario de Funciones, nivel C1-C2, Niveles de referencia para el español, epígrafes 3.17, 3.27 y 4.21.
} 


\section{Descripción}

Se trata de una actividad en parejas en la cual cada miembro desempeña un papel: A y B. Se trata de una pareja que pasa por un momento algo complicado y cada uno de los miembros inicia la conversación con un objetivo distinto. El estudiante que tiene el papel A está decidido a terminar con la relación y a comunicárselo lo antes posible a su pareja. En cambio, B quiere animar la relación y proponer a A una cena romántica y un viaje a Venecia.

El profesor reparte las tarjetas con la información y cada pareja desempeña el papel que le ha tocado.

\subsubsection{Tercera actividad: Un piso compartido}

Objetivo: practicar la entonación de (des)cortesía

Nivel: $\mathrm{C} 1$

Tiempo: unos 10 minutos

Destrezas: interacción

Tipo de agrupamiento en clase: grupos de tres

Material: tarjetas

Se trata de una actividad que puede realizarse en parejas o grupo pequeño. Vamos a proponer la realización en grupo de tres en la que cada alumno desempeña un papel. La actividad consiste en quejarse y expresar el malestar por un problema de convivencia. El alumno A se queja con entonación descortés a $\mathrm{B}$, aunque con estructuras lingüísticas ${ }^{9}$ más bien "neutras." Sin embargo, B se altera ${ }^{10}$ y resulta totalmente descortés. Entonces, el alumno $\mathrm{C}$ tiene que poner paz y ser objetivo y atenuador.

La situación sería la siguiente:

A. Estás harto de tu compañero de piso. A menudo se deja el grifo abierto, las luces encendidas o repasa durante cinco minutos el interior de la nevera. Las facturas de agua y luz se han disparado desde que él comparte piso contigo. Además, no tiene ningún tipo de conciencia ecológica. Esta situación no puede continuar así y hoy mismo lo quieres solucionar.

B. Tu compañero de piso está obsesionado con el consumo energético. ¡iTiene unas manías!! ¡No se puede abrir la nevera más de cinco segundos! Hoy le dirás que si no te deja tranquilo de una vez, te buscarás otro piso.

\footnotetext{
${ }^{9}$ Sugerimos la introducción de las funciones 2.4. "Valorar" (me parece + adj./SN+lo que...; resulta+adj./SN, 2.5. "Expresar aprobación y desaprobación" (me parece lamentable..) y 2.10. "Expresar desacuerdo" (Yo no diría lo mismo; no lo veo así).

${ }^{10}$ Puede utilizar las estructuras correspondientes a la función 3.16 "Expresar hartazgo" (Estoy hasta la coroni1la/las narices/aquí de...; hasta aquí hemos llegado).
} 
Comprendes al compañero A. Tú también eres consciente del medio ambiente, pero crees que quizás resulte algo pesado en este tema. En cuanto a $\mathrm{B}$, crees que habría que convencerlo de otra forma para que tenga un cambio de actitud.

\subsubsection{Cuarta actividad: El malentendido}

Objetivo: practicar la entonación de (des)cortesía

Nivel: $\mathrm{C} 1-\mathrm{C} 2$

Tiempo: unos 15 minutos

Destrezas: interacción

Tipo de agrupamiento en clase: en parejas

Material: tarjetas

Esta actividad tiene como objetivo poner en práctica especialmente la atenuación y las funciones lingüísticas correspondientes al nivel $\mathrm{C} 1-\mathrm{C} 2$ tales como "pedir un favor de forma atenuada" y "aceptar y rechazar una propuesta, ofrecimiento o invitación". ${ }^{11}$ Algunas de las estructuras lingüísticas que ofrecemos para estas funciones pertenecen al nivel C2.

Proponemos una actividad de role-play en parejas que consiste en una conversación de tipo formal en un ambiente laboral entre un subordinado y un cargo superior. En la conversación se produce un malentendido por parte del subordinado. Al tratarse de un contexto formal y jerarquizado, deberán utilizarse estructuras lingüísticas de rechazo muy atenuadas tanto desde el punto de vista morfológico y sintáctico como fonético.

Como actividad previa, introducimos en clase el tema de los malentendidos respecto a la intención del hablante. Pedimos a los alumnos que expliquen ejemplos sobre este tipo de errores en su propia lengua o en español. Tras comentarlos entre todos, les presentamos el caso de un superior que pide simplemente un favor a un subordinado, pero que es interpretado por parte del segundo como una invitación de tipo personal.

Otra manera de proceder, consistiría en comentar que se producirá un malentendido, pero sin concretar. En esta opción, dividimos a los alumnos según el papel que desempeñarán y les damos las instrucciones por separado, es decir, pediremos a uno de los grupos que salga del aula. Informamos entonces a los alumnos en el papel de jefe sobre el tipo de estructuras y la entonación cortés que deben emplear. Puesto que se trata de una conversación formal, repasamos algunas estructuras que podrían utilizar (véase el cuadro a continuación).

“Me haría el favor de...?”

“Sería tan amable de...?”

"Le agradecería que me acompañara..."

Función 4.2. p. 221. Niveles de referencia para el español, nivel C1-C2.

${ }^{11}$ Función 4.2. Pedir un favor de forma atenuada, inventario de Funciones (C1-C2), p. 221. Función 4.16. Aceptar una propuesta, ofrecimiento o invitación, inventario de Funciones (C1-C2), p. 232. 
Informamos también a los alumnos en el papel de subordinado sobre el malentendido que se producirá y les damos algunos ejemplos correspondientes a la función 4.17. "rechazar" (p. 232). Proponemos la introducción de estructuras de nivel $\mathrm{C} 1$ y $\mathrm{C} 2$ como las siguientes.

"Precisamente/justamente... no puedo".

"Lamento tener que rechazar su amable invitación, pero... me resulta completamente imposible.".

Antes de iniciar la actividad, explicamos a los dos grupos de estudiantes que la conversación debe ser formal en su totalidad y constar de una introducción (el superior tiene que presentar la situación antes de pedir el favor e insistir y el subordinado, utilizar las estructuras de rechazo, alegar una excusa creíble y resolver cortésmente la conversación). Les comentamos que pueden añadir información complementaria y por lo tanto, deberán improvisar según se desarrolle la conversación.

Después de estas indicaciones, pedimos a los alumnos que se agrupen en parejas (jefe y subordinado) y les repartimos unas tarjetas con la información básica para que puedan desarrollar la actividad.

\section{$\boldsymbol{A}$}

Eres el jefe del departamento de marqueting. Esta tarde tienes que asistir a una conferencia y luego a una cena. Le pides a tu secretaria de confianza que te acompañe, porque no te apetece ir solo y porque la vas a necesitar para que tome algunas notas. Tienes que insistir amablemente.

Ofrecemos a continuación un ejemplo de tarjeta A (papel de jefe) y otro de B (papel de secretaria).

Después de la práctica, pedimos a una pareja de alumnos que vuelva a interpretar su papel delante de toda la clase y que el resto escuche atentamente. Tras la interpretación, se comenta entre todos si las estructuras les han parecido suficientemente atenuadas o si, por el contrario, ellos, en el lugar del jefe, se hubieran molestado por el rechazo de la secretaria.

\section{$B$}

El jefe te pide que lo acompañes a una reunión y a una cena. A tí no te apetece en absoluto y además crees que lo que pretende es tirarte los tejos. Últimamente es muy amable... 


\subsubsection{Quinta actividad: La excusa}

Objetivo: practicar la atenuación

Nivel: $\mathrm{C} 1$

Tiempo: unos 30 minutos

Destrezas: interacción

Tipo de agrupamiento en clase: en parejas

Material: tarjetas

En esta actividad vamos a proponer la práctica de la atenuación fonética en estructuras lingüísticas descorteses, así como varias funciones lingüísticas correspondientes al nivel C1.

Nuestro objetivo es trabajar algunas funciones en una actividad de role-play en la que también se practicará la atenuación, pero de forma más intensa que en la actividad cuarta, porque en este caso no coincidirá con un tipo de estructuras corteses desde el punto de vista léxico, sintáctico y morfológico.

La situación que proponemos consiste en recrear una conversación entre dos amigos. Del mismo modo que en la actividad anterior, se repartirán unas tarjetas con el contexto y las intenciones de cada interlocutor.

Antes de iniciar la actividad podemos repasar algunas estructuras correspondientes a la función "pedir objetos" (función 4.3. del inventario Funciones (C1-C2), p. 222). Algunas de las estructuras pertenecen al nivel $\mathrm{C} 2$. En el cuadro siguiente reproducimos algunos ejemplos:

¿Podrías hacerme/me harías el favor de dejarme/prestarme/traerme...? ¿Tendrías la amabilidad/bondad de darme/dejarme/prestarme/... + SN?

(Te) estaría (+intensificador) agradecido si me dejaras/prestaras/trajeras...

También podemos repasar las estructuras correspondientes a la función 4.7. Responder a una orden, petición o ruego, epígrafe 4.7.3. Negándose a su cumplimiento (de forma tajante) ${ }^{12}$. También en este caso hemos añadido algunas estructuras que pertenecen al nivel C2.

\footnotetext{
${ }^{12}$ P. 226-227. Inventario de Funciones, nivel C1-C2.
} 


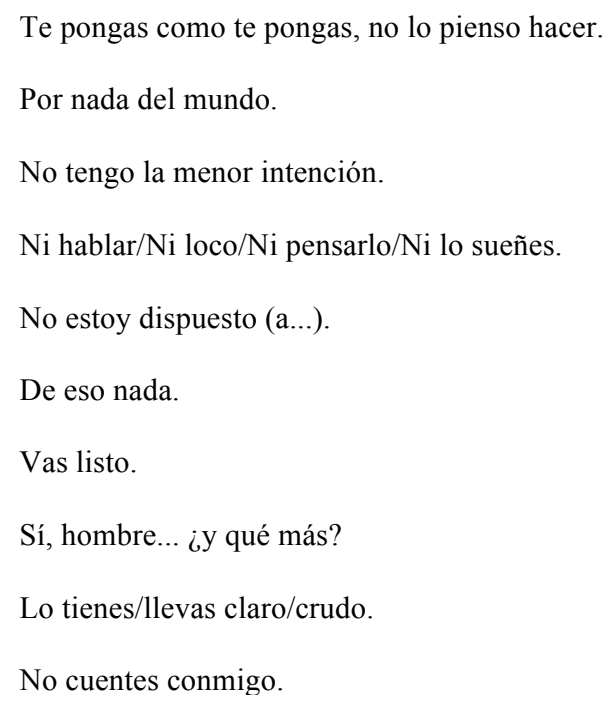

Como puede observarse, las estructuras que hemos elegido resultan bastante tajantes, por lo que las intentaremos atenuar mediante una entonación adecuada. Antes de realizar la actividad propuesta, vamos a proponer a los alumnos una breve práctica de las estructuras y de la entonación.

Para ello repartiremos una lista (puede ser una para dos alumnos) en la que aparezcan unas veinte peticiones de objetos y de favores ${ }^{13}$. Exponemos algunos ejemplos en el cuadro siguiente.

1. “Podría pasar unos días en tu piso, cuando te vayas de vacaciones?”

2. “¿Me prestarías tu bici?”

3. "Necesitaría que me dejaras unos doscientos euros."

4. “Podrías dejarme la moto para un par de horas?”

5. “Aquel vestido azul que tienes... ¿me lo podrías prestar para el sábado por la noche?"

El objetivo de esta actividad previa es comprobar si los alumnos son capaces de reproducir una entonación muy atenuadora con un tipo de estructuras que pueden resultar muy tajantes y descorteses.

\footnotetext{
${ }^{13}$ El profesor puede inventar la lista, pero también se podría elaborar entre toda la clase.
} 
La forma de proceder será la siguiente. Un alumno cualquiera se dirigirá a otro y le pedirá uno de los objetos o favores de la lista, el cual deberá responderle con alguna de las estructuras propuestas y con una entonación muy atenuada. Mediante esta actividad previa, el profesor podrá controlar las producciones de los alumnos e intervenir en caso necesario. Además, todos los alumnos tendrán la oportunidad de participar y de comprobar la adecuación de sus intervenciones.

Después de esta práctica global, es decir, de todo el grupo, pedimos a los alumnos que se agrupen en parejas y les repartimos unas tarjetas con la información básica para que puedan desarrollar la actividad de role-play.

Ofrecemos a continuación un ejemplo de tarjeta A y otro de B.

\section{$A$}

Esta noche has quedado con alguien especial para ir a un concierto en las afueras. Te iría muy bien tener un coche para desplazarte hasta allí. Se lo pides a tu mejor amigo.

Ya te lo dejó en una ocasión y crees que te lo volverá a prestar si le insistes un poco.

\section{$B$}

Uno de tus mejores amigos te pide el coche para salir esta noche. Ya se lo dejaste en una ocasión y te lo devolvió con un par de abolladuras. Es un buen amigo pero conduce fatal y no estás dispuesto a dejárselo otra vez. Busca una excusa y, ante su insistencia, sé algo tajante, pero al mismo tiempo usa una entonación atenuadora.

Después de la práctica, pedimos a una pareja de alumnos que vuelva a interpretar su papel delante de toda la clase y que el resto escuche atentamente. Tras la interpretación, se comenta entre todos si las estructuras les han parecido suficientemente atenuadas o si, por el contrario, les han resultado todavía muy tajantes.

\section{Conclusiones}

El estudio de las funciones pragmáticas del componente melódico posee escasa tradición en el ámbito hispánico. En el caso de las funciones corteses, el componente fónico ha sido el gran olvidado. Los estudios realizados o bien evitan mencionarlo, o lo hacen de forma superficial, o bien tratan de buscar soluciones descriptivas de compromiso. La investigación que hemos realizado trata de llenar este vacío clasificando los rasgos de (des)cortesía del 
español, a partir del análisis acústico y perceptivo de un corpus de habla espontánea y, al mismo tiempo, ofrece unas propuestas didácticas pensadas para alumnos extranjeros de español profesional. Las propuestas han sido divididas en dos partes. En la primera se presenta el contenido mediante una actividad de percepción que permite la presentación de diversas muestras de entonación de (des)cortesía. A continuación se realiza una práctica de identificación para proporcionar un mayor control a los alumnos sobre el contenido que queremos trabajar. Se trata de una práctica en la que el profesor puede intervenir y estar pendiente de las producciones de los estudiantes para identificar posibles dificultades o problemas tanto en la producción como en la percepción de la entonación de (des)cortesía. En la segunda parte, ofrecemos la posibilidad de realizar varias actividades interactivas centradas en la entonación, que permiten también el repaso o la introducción de funciones lingüísticas que encajan en las diversas situaciones o contextos creados en las actividades.

Este tipo de actividades centradas en la entonación de (des)cortesía no se trabaja en los manuales de ELE y creemos que es un contenido que resultaría conveniente introducir, especialmente en los manuales de español con fines profesionales, ya que la cortesía, en muchas ocasiones, es la clave para la rentabilidad de un negocio o, simplemente, para que la comunicación sea eficaz. Un cliente, por ejemplo, que ha sido cortésmente tratado, tendrá mucha más confianza hacia el empleado y la empresa, el producto, la información o el servicio que ha recibido. Por tanto, la cortesía se convierte en una herramienta de comunicación que puede desencadenar un torrente de información importantísima para el buen funcionamiento de un negocio.

\section{REFERENCIAS BIBLIOGRÁFICAS}

Cantero Serena, F. J. (2002). Teoría y análisis de la entonación. Barcelona: Edicions de la Universitat de Barcelona.

Cantero Serena, F. J.; R. Alfonso; M. Bartolí; A. Corrales y M. Vidal (2005). "Rasgos melódicos de énfasis en español", en Phonica, 1: 1-40.

Cantero Serena, F. J. y Font-Rotchés, D. (2007). "Entonación del español peninsular en habla espontánea: patrones melódicos y márgenes de dispersión”, en Moenia, 13: 69-92.

Cantero Serena, F. J. y Mateo M. (2011). "Análisis melódico del habla: complejidad y entonación en el discurso", en Oralia, 14: 105-127.

Devís Herraiz, E. (2011). "La entonación de (des)cortesía en el español coloquial”, en Phonica, 7: $36-79$.

Devís Herraiz, E. (en prensa). "Entonación de cortesía involuntaria en el español hablado por brasileños", Estudos do Espanhol, Brasilia: Pontes.

Hidalgo, A. (2009). "Modalización (des)cortés y prosodia: estado de la cuestión en el ámbito hispánico", en Boletín de Filología de la Universidad de Chile, XLIV/1: 161-195.

Instituto Cervantes (2006). Plan curricular del Instituto Cervantes. Niveles de referencia para el español, Madrid: Biblioteca nueva.

Quilis, A. (1993). Tratado de fonética y fonología española. Madrid: Gredos. 